\title{
ALFABETIZAÇÃO COM BASE EM EVIDÊNCIAS CIENTÍFICAS
}

\author{
LITERACY BASED ON SCIENTIFIC EVIDENCE
}

\author{
ALFABETIZACIÓN BASADA EN EVIDENCIA CIENTÍFICA
}

\author{
Suzana Schwartz ${ }^{\mathrm{i}}$ \\ Maurício Aires Vieira ${ }^{\text {ii }}$ \\ Ana Cristina Rodrigues ${ }^{\text {iii }}$
}

\begin{abstract}
Resumo: Evidências científicas são um conjunto de informações coletadas metodologicamente sobre um objeto de estudo específico. Esse texto analisa se há evidências científicas que sustentam ser possível alfabetizar, em um ano letivo, a todos os alunos. O caminho metodológico foi percorrido através da revisão da literatura sobre o tema, a identificação de propostas que sugerem um outro tempo para concretizar o processo de alfabetização, bem como com a aplicação de um questionário com professores alfabetizadores, perguntando suas percepções sobre as razões de alguns alunos aprenderem em um ano letivo e outros não. Com base na análise do conteúdo das respostas, confrontadas com a revisão de literatura sobre o tema, concluímos que os motivos apontados se mantêm estáveis entre os professores alfabetizadores há muitos anos e não justificam a não aprendizagem em um ano letivo, não são sustentados por evidências científicas. Essas indicam ser possível alfabetizar todos os alunos em um ano letivo, desde que o professor alfabetizador tenha reconstruído o conhecimento científico sobre como se ensina a ler e a escrever, ressignificado e incorporado esses pressupostos teóricos com coerência em sua prática docente.
\end{abstract}

\begin{abstract}
Scientific evidence is a set of information collected methodologically about a specific object of study. This text examines whether there is scientific evidence that maintains that it is possible for all students to become literate in an academic year. The methodological path was followed by reviewing the literature on the topic, identifying proposals that suggest another time to make the literacy process concrete, as well as applying a questionnaire with literacy teachers, asking their perceptions about the reasons for some students learn in an academic year and others do not. Based on the analysis of the content of the responses, compared to the literature review on the topic, we conclude that the reasons given have remained stable among literacy teachers for many years, do not justify not learning in an academic year and they are not supported by evidence scientific. These indicate that it is possible to literate all students in a school, provided that the literacy teacher has reconstructed scientific knowledge about how to teach reading and writing, reframing and incorporating these theoretical assumptions with coherence in their teaching practice.
\end{abstract}

Resumen: La evidencia científica es un conjunto de información recopilada metodológicamente sobre un objeto de estudio específico. Este texto analiza si existe evidencia científica que respalde la posibilidad de alfabetización, en un año académico, para todos los estudiantes. El camino metodológico fue seguido por la revisión de la literatura sobre el tema, identificando propuestas que sugieren otro momento para concretar el proceso de alfabetización, y aplicando un cuestionario con maestros de alfabetización, preguntando sus percepciones sobre las razones de algunos los estudiantes aprenden en un año académico y otros no. Con base en el análisis del contenido de las respuestas, en comparación con la revisión de la literatura sobre el tema, concluimos que las razones dadas se han mantenido estables entre los maestros de alfabetización durante muchos años, no justifican no aprender en un año académico y no están respaldadas por evidencia científica. Esta indica que es posible alfabetizar a todos los estudiantes en una escuela, siempre que el maestro de alfabetización haya reconstruido el conocimiento científico sobre cómo enseñar lectura y escritura, reformulando e incorporando estos supuestos teóricos con coherencia en su práctica docente.

Palavras-chave: Alfabetização; evidências científicas; aprendizagem. 
Keywords: Key words: Literacy; scientific evidence; learning.

Palabras claves: Cuerpos negros; Violencia; Análisis del discurso.

\section{INTRODUÇÃO}

Não é o objetivo desse texto refletir e/ou informar detalhes minuciosos sobre o conceito de evidências científicas. No entanto, como ele aparece no título e está sendo utilizado em relação ao tema do texto - alfabetização - é preciso esclarecê-lo, já que em ciência os conceitos podem ser polissêmicos e interpretados com base em diversas perspectivas. Daí a necessidade de esclarecer a nossa.

As divergências e convergências sobre este conceito estão relacionadas também com as diferenças inerentes as ciências - humanas, exatas, naturais, sociais, entre outras - que se dedicam ao estudo de diferentes fenômenos ou ao de perspectivas diversas dos mesmos fenômenos.

O conjunto de elementos utilizados para apoiar ou refutar uma hipótese ou teoria alcançadas através do método científico constituem evidências. Seus padrões variam de acordo com o campo de pesquisa, sendo, geralmente, baseadas nos resultados da análise estatística, na observação e experimentação metodológica.

Pesquisas geralmente iniciam com a coleta de evidências científicas que emergiram de outros estudos sobre o tema, através de uma revisão sistemática da literatura. Depois da análise das informações coletadas através desse instrumento metodológico, baseada em fontes confiáveis e reconhecidas pela comunidade científica, os estudos mantêm ou modificam seus pressupostos iniciais, adaptando seus objetivos e questões norteadoras.

No caso de um estudo sobre o tema da alfabetização, com o objetivo de contribuir para o avanço dessa aprendizagem em um contexto onde ela está sendo problemática, é necessário identificar as evidências cientificas relacionadas ao conhecimento sobre o processo de aprendizagem humana, a definição do conceito de alfabetização, ao contexto do fenômeno no local pesquisado, as convergências e divergências teóricas e práticas.

É necessário que a revisão da literatura sobre o tema seja consistente, abrangente, buscando evidências em diferentes estudos, perspectivas, contextos. Analisando convergências e divergências, limites e possibilidades. Há diversas orientações epistemológicas que embasam estudos sobre o processo de alfabetização. As mais conhecidas e reconhecidas pela comunidade científica se referem a métodos e/ou teorias.

Há defensores de métodos como o fônico, o global, o sintético, o analítico. E outros que defendem perspectivas teóricas sobre como os sujeitos aprendem, como o 
construtivismo, o sociointeracionismo, baseados em estudos de Piaget e de Vygotsky, inicialmente.

Alguns pressupostos desses métodos e teorias não são, por si só excludentes. Há estudos que apontam sucesso em todos eles. Nesse sentido, o que ficou conhecido como "batalha dos métodos", quando defensores de um ou de outro debatiam no sentido de provar que o seu era melhor, mais adequado, mais produtivo, não é a nossa questão.

Conhecer profundamente as diferentes linhas de alfabetização é essencial para separar o que está ultrapassado do que funciona e para escolher as práticas mais eficientes para cada aluno e cada ocasião. $\mathrm{Na}$ sala de aula, o papel do professor é desenvolver estratégias para que todos os alunos aprendam.

Um professor competente percebe que enfoques diferentes não aprisionam e sim ampliam as opções para ensinar. O que determina a aprendizagem é o tipo de intervenção que o professor faz com base no conhecimento científico sobre como os sujeitos aprendem.

O que a ciência confirma é que o ser humano nasce com potencial para aprendizagem e que os limites e possibilidades individuais ainda não foram definidos. É possível afirmar, com base em evidências científicas, que o ser humano aprende pensando, elaborando relações entre um conhecimento prévio e uma nova e/ou diferente informação.

Outro conhecimento científico relevante para o processo de alfabetização é a importância da influência do meio. Ou seja, um sujeito que nasceu e vive em um ambiente alfabetizador rico, com diversos portadores de texto (cercado por livros, revistas, placas de ruas, nome de lojas, quadros, bilhetes, receitas), com pessoas alfabetizadas, que fazem uso social da escrita, vai ter conhecimento prévio mais elaborado do que outro que vive em um contexto quase ágrafo, cujos pais ou responsáveis são analfabetos funcionais ou não. Consequentemente terá mais elementos para ser bem sucedido na aprendizagem formal da leitura e da escrita, independentemente do método ou teoria a que for submetido.

Afirmar que uma proposta é baseada em evidências científicas significa que, depois de realizar uma ampla revisão sobre o tema, uma foi escolhida baseada em uma hipótese entre as possíveis. Não significa que outras propostas diferentes não sejam baseadas nesse tipo de evidências, científicas.

A maioria dos países que melhoraram a alfabetização nas últimas décadas - como Portugal - basearam as políticas públicas nas evidências das ciências cognitivas da leitura (ACADEMIA BRASILEIRA DE CIÊNCIAS, 2011). Essa área do conhecimento 
apresenta um conjunto de evidências sobre como as pessoas aprendem a ler e a escrever e como é possível ensiná-las de modo mais eficaz (SNOWLING; HULME, 2013).

Concluindo a introdução, explicitando conceitos, o de alfabetização que norteia esse texto é o de um processo inacabado, que habilita o sujeito a ler, produzir e compreender qualquer tipo de texto que desejar e/ou necessitar (SCHWARTZ, 2007). Esse conceito é coerente com o que afirma Bauman sobre aprendizagem "aprender é este vaivém sem fim de desconstrução e reconstrução, no qual nos esquematizamos e nos liquefazemos. (BAUMAN, 2007, p 34)".

Nesse contexto, reconhecendo que ensinar a ler a escrever é trabalho para profissionais - professores - e que há evidências científicas que orientam essa prática para o sucesso, questionamos:

\section{Aprender a ler e a escrever em um ano letivo é possível? Por que ainda há quem não aprenda?}

A Base Nacional Comum Curricular (BNCC) é o documento que vai nortear os currículos dos estados e municípios de todo o Brasil e regulamenta as aprendizagens essenciais a serem trabalhadas nas escolas brasileiras públicas e particulares de Educação Infantil, Ensino Fundamental e Ensino Médio, contém modificações relacionadas ao processo de alfabetização.

Ela explicita que "a alfabetização das crianças deverá ocorrer até o segundo ano do ensino fundamental, com o objetivo de garantir o direito fundamental de aprender a ler e escrever". A mudança pretende assegurar às crianças pobres o mesmo "direito dos alunos de classe média, que se alfabetizam com média inferior à média das escolas públicas" (Mendonça, 2017). ${ }^{1}$ As estatísticas informam que a não aprendizagem da leitura e da escrita se concentra significativamente nas escolas públicas, que em escolas particulares quase não existe preocupação com esse processo. Por que será que isso acontece? E por que motivos?

No entanto, há evidências científicas de que é possível ensinar e aprender a ler e a escrever a todos os alunos em um ano letivo (TEBEROVSKY, 2005; NEMIROVSKY, 2005, TOLCHINSKY, 2005, SCHWARTZ, 2007) se e quando o processo foi coordenado por um professor alfabetizador que reconstruiu e ressignificou o conhecimento cientificamente construído sobre esse processo.

Para contribuir na reflexão crítica sobre a adequação do tempo para alfabetizar sugerido pela BNCC, necessitamos pensar sobre a formação do professor alfabetizador,

\footnotetext{
${ }^{1}$ Declaração do Ministro da Educação, da época, no Jornal Nacional, em 6 de abril de 2017. 
suas concepções, crenças, experiências vivenciadas, para explicar/compreender (MORIN, 2000), como ele percebe sua prática, suas estratégias, bem como as causas/motivos que apontam para justificar que alguns alunos aprendem e outros não.

\title{
O PROFESSOR ALFABETIZADOR
}

\begin{abstract}
A falta de alinhamento entre a teoria da formação inicial e a prática do dia a dia na escola é uma questão bem conhecida dos professores. Com a implementação da Base Nacional Comum Curricular (BNCC), esse desafio ganha uma nova proporção. "Vamos ter que mexer muito nos cursos", resume Guiomar Namo de Mello, diretora da Escola Brasileira de Professores e integrante da equipe técnica da BNCC...2
\end{abstract}

Trabalhamos com a formação de professores alfabetizadores há muitos anos. Ao longo dos componentes específicos de alfabetização, apresentamos o histórico da escrita, seus usos e funções ao longo do tempo, os diferentes métodos utilizados, teorias e teóricos, descrevemos a pesquisa de Ferreiro e Teberosky (1979) conhecida por psicogênese da língua escrita, analisamos as ideias e concepções que diferenciam a alfabetização do letramento (FERREIRO, 2003, 2010; GADOTTI, 2005; WEISZ, 2016; COLELLO, 2003; SOARES, 2003; KLEIMAN, 1995), buscando a coerência na escolha dos conceitos que vamos utilizar. Caracterizamos o fenômeno do alfabetismo funcional, discutimos os diferentes indicadores de avaliação da aprendizagem da leitura e da escrita e os índices atuais de aprendizagem no contexto brasileiro ${ }^{3}$.

Quando introduzimos em sala de aula o tema da psicogênese da língua escrita, mostramos exemplos de escritas de sujeitos em processo de alfabetização, e solicitamos que analisem e digam o que é possível afirmar que os sujeitos SABEM sobre a escrita. Explicamos que nessa tarefa é proibido utilizar as palavras "não" e "ainda".

Os alunos, em geral, têm muita dificuldade em realizar a proposta. A maioria inicia a frase dizendo que se pode dizer que o sujeito "ainda...", que sujeito "não conhece” ou "só consegue...". Os próprios alunos percebem que isso acontece, e comentam: "como é difícil olhar o que o sujeito sabe, professora”. Concordamos com eles. Ampliamos essa percepção, sugerindo que esse "olhar" que busca o "não", ou o que "falta", é o olhar que muitas vezes não consegue enxergar o processo vivenciado pelo sujeito ao longo da aprendizagem da leitura e da escrita. Que não compreende o modo como o sujeito

\footnotetext{
${ }^{2}$ Disponível em https://novaescola.org.br/conteudo/11751/a-formacao-precisa-deixar-de-ser-problema-evirar-solucao acessado em 27/05/2018.

${ }^{3}$ Indicador Nacional de Alfabetismo Funcional (INAF) disponível em http://www.ipm.org.br/ptbr/programas/inaf/relatoriosinafbrasil/Paginas/default.aspx acessado em 26/08/2016.
} 
aprendiz pensa, reflete, compara, analisa, elabora e testa suas hipóteses. Não compreende por que não reconstruiu, não ressignificou para si mesmo o conhecimento cientificamente produzido sobre como se ensina e como se aprende a ler e a escrever.

E, pode que isso aconteça também porque, como afirma Tardif (1999, p. 20), "uma boa parte do que os professores sabem sobre o ensino, sobre os papéis do professor e sobre como ensinar, provém de sua própria história de vida e, sobretudo, de sua história de vida escolar", o que faz com que a tendência seja repetir o método com que foram alfabetizados, no decorrer de sua vida.

Ao longo dos anos, os métodos tradicionais foram considerados inadequados para ensinar a todos. Porém, eles parecem se perpetuar em várias salas de aula. Muitas vezes de forma escondida, um pouco envergonhada, professores ensinam como aprenderam, recorrendo a atividades como a caligrafia e o uso de cartilhas. Fazem isso provavelmente porque não sabem, não aprenderam a fazer diferente ou de outra forma.

Outra hipótese nos é oferecida por Lyra e Custódio (2019) que percebem ser as crenças educacionais como elaborações internas, individuais, construídas com base nas suas experiências pessoais e que condicionam o processo de decisão didático-pedagógica dos professores, influenciando antes, durante e após sua atuação docente. Afirmam também que muitas vezes, o professor atua de acordo com suas crenças sem suficiente reflexão crítica da influência dessas sobre sua atuação (p.144).

Nesse contexto, ao longo do tempo em que trabalhamos com alfabetização na educação superior temos tido o prazer de conviver com ótimos alunos. Esforçados, persistentes, estudiosos, interessados. No primeiro dia de aula, realizamos as apresentações dos alunos, da professora e do componente. $\mathrm{Na}$ apresentação dos participantes, solicitamos que relatem para o grupo o modo como foram alfabetizados. Passam-se os anos, e ainda não encontramos um aluno que tenha aprendido de forma diferente do método tradicional. Mudam as cartilhas, mudam os materiais, mas os pressupostos ficam inalterados. Cópia, repetição, memorização, "ba-be-bi-bo-bu” (CAGLIARI, 1998).

O ser humano costuma ter medo de abandonar o que conhece em troca de algo "novo". No caso da alfabetização, o "argumento" mais utilizado por professores alfabetizadores, em cursos de formação continuada ou palestras, para justificar o uso de métodos tradicionais nas aulas de alfabetização em lugar de algo "novo", diferente, é o "eu aprendi assim...".

Implícito nessa frase parece estar a percepção de que não há a necessidade de mudar esse ensino, pois aprenderam desse modo e chegaram onde quiseram chegar. Estão 
convictos de que é possível continuar a ensinar e a aprender com o ba-be-bi-bo-bu, mesmo diante dos indicadores alarmantes de analfabetismo funcional, os de não aprendizagem na alfabetização, não parecem refletir criticamente sobre que tipo de leitor e escritor desejam contribuir para formar. Na tentativa de compreender os motivos do medo de mudar a prática, elaboramos a hipótese de que, na percepção dos professores, trabalhar a alfabetização reconstrutivamente, pressupõe ausência" de método, o que contribui para que se sintam inseguros. Como não reconstruíram e não ressignificaram o conhecimento científico sobre como os sujeitos aprendem, se sentem perdidos, sem saber como começar.

Os que conhecem a teoria, sabedores que precisam partir do conhecimento prévio dos alunos, se questionam: será que vou saber diagnosticar o que já sabem? Serei capaz de realizar intervenções adequadas a esses saberes ao longo das aulas? Como saber se estou agindo bem? O que dizer para os pais para explicar que os cadernos não estão cheios de cópias? Como suportar a pressão dos colegas que trabalham diferente, que dizem que "na prática a teoria é outra"?

Os alunos de cursos de licenciaturas também resistem a mudanças e explicitam, quando apresentados aos achados da pesquisa de Ferreiro e Teberosky (1979), dúvidas semelhantes às dos professores. Para que mudar o jeito de trabalhar a alfabetização? Não aprendemos todos do outro jeito? Muitos protestam veementemente, afirmando que o importante é conseguir que leiam algo! Depois veremos como vão compreender!

E, após dois semestres argumentando, oportunizando que vejam na prática como os alfabetizandos elaboram hipóteses sobre a escrita, fazendo testagens com crianças e adultos em processo de alfabetização; através de vídeos; compartilhando os índices brasileiros de analfabetismo funcional divulgados pelo INAF; comentando o absurdo que são os índices de alunos chegando aos anos finais da educação básica semianalfabetos (os poucos que chegam...); justificando que os usos sociais da escrita de hoje são diferentes dos de quando eles foram alfabetizados; que as competências demandadas são outras; que queremos contribuir para formar pessoas que leiam, produzam e compreendam diferentes tipos de textos que desejarem ou necessitarem, e que essa aprendizagem qualifique suas existências, os alunos finalizam o semestre parecendo convencidos de que é preciso mudar o jeito de ensinar a ler e a escrever sob pena de contribuir para a formação de mais analfabetos funcionais.

Acompanhamos, ao longo do processo, suas dificuldades em abandonar o "barco seguro" do "eu aprendi assim com ba-be-bi-bo-bu". 
No entanto, quando esses mesmos alunos, que parecem estar "convencidos" da necessidade de mudar a prática pedagógica alfabetizadora tradicional para contribuir para formar bons leitores e escritores, chegam ao estágio supervisionado, se deparam com contradições alarmantes, como o da professora "titular" na escola onde vão estagiar, que solicita conteúdos e modos de trabalhar coerentes com o método tradicional, aquele com que os estagiários também foram alfabetizados.

Relatam que "são obrigados" a fazer o que a professora titular pede, que precisam concluir o estágio, e a mesmice parece que se perpetua nesse ciclo perverso de não aprendizagens, manutenção do conhecido, medo do desconhecido. Freire (2000) afirmou que medo todo mundo tem, o que não se pode é permitir que "o medo nos paralise", nesse caso, ao ponto de aceitarmos sermos incoerentes com nossas concepções sobre como se ensina e, principalmente, como o sujeito aprende a ler e a escrever.

Um processo semelhante parece acontecer com alguns grupos que trabalham no PIBID (Programa Institucional de Bolsa de Iniciação à Docência) nas escolas, que relatam práticas que presenciam em salas de aulas alfabetizadoras, sem coragem de questionar a professora titular, profissional que geralmente também participou do Pacto Nacional pela Alfabetização na idade certa (PNAIC) ${ }^{4}$, motivo pelo qual temos alguns questionamentos sobre a contribuição positiva que esses programas trazem para os professores (futuros e atuais) que neles estão inseridos. A comparação dos resultados das edições de 2014 da Avaliação Nacional da Alfabetização (ANA) e a de 2016 revela uma estagnação no desempenho dos alunos (INEP, 2018).

Foram avaliados pelo ANA (2016) 2.456 .132 estudantes do terceiro ano do ensino fundamental. Segundo os resultados 54,73\% apresentaram desempenho insuficiente no exame de proficiência em leitura. Em escrita, 33,95\% estavam em níveis insuficientes (1, 2 ou 3). $54,46 \%$ dos estudantes tiveram desempenho abaixo do adequado em matemática, o que significa que não eram capazes, por exemplo, de calcular adição de duas parcelas com reagrupamento, nem de associar o valor monetário de um conjunto de moedas ao valor de uma cédula.

O PNAIC sugere utilizar os três primeiros anos letivos para o ensino e aprendizagem da escrita: "o ciclo da alfabetização nos anos iniciais do ensino fundamental é um tempo sequencial de três anos, sem interrupções, dedicados à inserção da criança na cultura escolar, à aprendizagem da leitura e da escrita [...]" (PNAIC, p.17) ${ }^{5}$, ideia que foi contraposta na BNCC (2017), como já comentamos. No entanto, Grossi (2017), comenta

\footnotetext{
${ }^{4}$ Disponível em http://pacto.mec.gov.br/o-pacto acessado em 08/04/2019.

${ }^{5}$ Disponível em http://pacto.mec.gov.br/images/pdf/pacto_livreto.pdf acessado em 29/08/2019.
} 
que essa ideia da BNCC é "nova falácia criminosa" E complementa que "é preciso e é possível alfabetizar no $1^{\circ}$ ano... está mais do que comprovado cientificamente que se pode fazê-lo!”

Sobre o tema do tempo adequado para ensinar a ler e a escrever, concordamos com Grossi (2017) e com Demo (2012), que foi contundente na crítica à sugestão de três anos para alfabetizar na escola pública. Afirma o autor que ninguém no MEC ia querer isso para seus filhos, "é coisa típica para pobre" (p.24). Salienta também que "Grossi (2004) sempre defendeu que é possível alfabetizar no $1^{\circ}$ ano, até porque demorando três, é enorme o risco da criança não se alfabetizar mais" (IRIZAGA, 2002, apud DEMO 2012).

Nesse contexto, para identificar a percepção dos professores alfabetizadores sobre a problemática, realizamos uma pesquisa aplicada ao final de um curso de extensão de $80 \mathrm{~h}$ sobre teoria e prática alfabetizadora, no qual foram abordados e discutidos temas como: a psicogênese da língua escrita e a reconstrução do conhecimento, estratégias didáticas coerentes com essa teoria, como iniciar o processo de alfabetização, sugestões de atividades cotidianas para os diferentes níveis de alfabetização, dentre outros conteúdos. O questionamento direcionado para os professores alfabetizadores participantes foi: "considerando o que foi apresentado e debatido ao longo do nosso curso, por que acreditas que alguns alunos aprendem a ler e a escrever em um ano letivo e outros não"?

As quarenta e oito respostas recebidas foram analisadas com base na análise de conteúdo proposta por Moraes (2003) e agrupadas em categorias. Foram divididas em: responsabilizam o aluno, a família, o meio, o professor. A seguir, apresentamos o quadro I das respostas.

Quadro 1: Motivos apontados sobre a não aprendizagem

\begin{tabular}{|c|c|c|c|}
\hline Respostas & úmero & Responsabiliza & $\begin{array}{c}\text { Provável } \\
\text { concepção que embasa }\end{array}$ \\
\hline $\begin{array}{l}\text { Falta de estímulo, problemas } \\
\text { familiares, falta motivação e de ajuda dos } \\
\text { pais, falta de comprometimento com o } \\
\text { saber. }\end{array}$ & 15 & $\begin{array}{l}\text { Pais e/ou } \\
\text { responsáveis }\end{array}$ & Empirista \\
\hline $\begin{array}{l}\text { Falta de atenção e/ou interesse do } \\
\text { aluno. }\end{array}$ & 15 & Aluno & Empirista \\
\hline $\begin{array}{l}\text { Crianças tem seu momento certo } \\
\text { para aprender a ler e a escrever. Cada um } \\
\text { tem um tempo diferente, cada um tem } \\
\text { seu tempo, precisam de aula de reforço. A } \\
\text { criança necessita de maturidade cognitiva }\end{array}$ & 28 & Aluno & Inatista \\
\hline
\end{tabular}




\begin{tabular}{|c|l|l|c|}
\hline adequada. & & & \\
\hline Depende da genética. & 1 & Aluno/genética & Inatista \\
\hline $\begin{array}{l}\text { Desnutrição danifica o cérebro. } \\
\text { Problemas de aprendizagem: visão, } \\
\text { neurológicos etc. }\end{array}$ & 3 & Aluno & Inatista \\
\hline $\begin{array}{l}\text { Crianças com maior contato com } \\
\text { material escrito aprendem com mais } \\
\text { facilidade. }\end{array}$ & 12 & Meio & Empirista \\
\hline $\begin{array}{l}\text { Responsabilidade do professor, } \\
\text { como utilizar o conhecimento prévio do } \\
\text { aluno. }\end{array}$ & 4 & Professor & Construtivista \\
\hline
\end{tabular}

Fonte: Elaboração dos pesquisadores

Os motivos apontados pelos professores alfabetizadores têm se mantido estáveis ao longo dos anos. Esse fato parece encaminhar para a percepção que a formação de professores, concebida como “[...] uma trajetória de formação de indivíduos, intencionalmente planejada, para a efetivação de determinada prática social" (MARTINS, 2010, p.14) não parece estar contribuindo para modificar a percepção dos alfabetizadores em relação aos motivos da não aprendizagem da leitura e da escrita. Ao encontro dessa ideia, Gatti (2016) afirma que "universidades brasileiras não estão realmente formando professores $[. .]. "{ }^{6}$

Nesse contexto, com a clareza de que qualquer fenômeno precisa ser analisado tanto nas suas partes quanto no todo (MORIN, 1999, 2000), é importante trazer alguns elementos que podem contribuir para analisar criticamente essas respostas dos professores.

Informações divulgadas por pesquisa realizada pela Fundação Carlos Chagas (2008) ${ }^{7}$ sobre as composições curriculares dos cursos de Pedagogia no Brasil revelou que apenas $20,7 \%$ dos componentes obrigatórios desses cursos tratam de práticas de ensino, didáticas específicas e metodologia. Embora a pesquisa não seja recente, um breve olhar sobre os atuais componentes curriculares dos cursos de formação de professores pode ser suficiente para a percepção de que a proporção entre os componentes teóricos e os práticos parece estar se mantendo, ocorrendo poucas mudanças nos fluxogramas curriculares dos cursos.

${ }^{6}$ Disponível em http://www.revistaeducacao.com.br/especialista-afirma-que-universidades-brasileirasnao-estao-realmente-formando-professores/ acessado em 29/08/2016.

${ }^{7}$ GATTI, B. A. et al. Formação de professores para o ensino fundamental: instituições formadoras e seus currículos; relatório de pesquisa. São Paulo: Fundação Carlos Chagas; Fundação Vitor Civita, 2008. $2 \mathrm{v}$. 
Outra parte do fenômeno poderia estar relacionada com as informações divulgadas pelo ENEM (Exame Nacional do Ensino Médio, 2015). O INEP (Instituto Nacional de Estudos e Pesquisas Educacionais Anísio Teixeira) traçou um perfil dos alunos que fizeram o ENEM em 2015 e que manifestaram o desejo de ser professores. Apenas 3,2\% manifestaram terem escolhido a profissão de professor.

Pesquisas informais realizadas ao longo de nossas trajetórias acadêmicas permitem inferir que a maioria dos alunos de curso de Pedagogia não escolheu ser professor. Afirmam que ingressaram na Pedagogia por "ser o único curso em que consegui ingressar depois de várias tentativas para outro"; " por ser mais barato"; "por ser mais perto de casa", "por ser o único curso que tinha na minha cidade" e até porque "minha mãe queria que eu fosse professora". Esses motivos, dentre outros fatores políticos e culturais, precisariam ser modificados ao longo do curso.

Claxton (1984) vem ao encontro dessa ideia, quando ao expressar o conceito de motivação, afirma que para motivar alguém para algo seria preciso modificar as prioridades de um sujeito, contribuir para originar motivos diferentes dos iniciais que mobilizaram o sujeito para aquela ação. Para isso, outras prioridades necessitariam ser modificadas, tal como como sinaliza Demo (2008) "valorizar o docente, ainda é a estratégia mais promissora - nunca única ou isolada - de melhorar a aprendizagem escolar" (DEMO, 2008, p. 1).

Nesse sentido, ciente de que para descrever, analisar, interpretar, explicar/compreender informações coletadas para a pesquisa, é necessário considerá-las como interfaces de processos complexos, multidimensionais, não estáticos, investidos de interesses, de motivações e de significados diversos, apresento e analiso as categorias emergentes articulando com diferentes teóricos. É importante considerar que essa é uma das análises e interpretações possíveis para as informações coletadas, ciente que o mesmo fenômeno pode ter diferentes olhares e interpretações.

\section{A ANÁlise dos MOTIVOS}

O primeiro motivo (conforme quadro) se refere aos pais ou responsáveis. Para analisá-lo articulando-o com o motivo dois, (falta de atenção ou interesse dos alunos), é necessário, inicialmente, esclarecer qual o papel dos pais e qual o papel da escola e de seus professores no ensino e na aprendizagem dos alunos.

Escola é espaço profissional, professor é profissão e aluno também, pois no seu documento de identidade está escrito "profissão: estudante" (FREIRE, 2001). Professor é o profissional da aprendizagem (DEMO, 2011), o papel do professor é planejar e 
desenvolver estratégias para oportunizar que todos os seus alunos aprendam. Ou seja, o objetivo da profissão docente é a aprendizagem, que se dá, ou não, através do ensino.

E qual seria o papel dos pais no ensino e na aprendizagem dos conteúdos escolares dos filhos? Escolher a escola, matricular regularmente e desenvolver estratégias para que os filhos frequentem diariamente esse espaço. A democratização do acesso à escola tem garantido vagas para todos, existindo, inclusive, legislação que pune a família que não matricula e não leva seus filhos para o ambiente escolar, além de ser oferecida bolsa-escola para os pais e/ou responsáveis que provarem dela necessitar para cumprir seu papel.

Sendo assim, quando os professores apontam a ausência de motivação adequada dos pais para justificar a não aprendizagem dos alunos, parecem não ter clareza em relação ao papel desses pais e nem do seu papel nos processos de ensino e de aprendizagem. Cabe ao professor planejar modos de seduzir o aluno, de fazer com que ele atribua significado às aprendizagens que precisa reconstruir, que deseje fazê-lo. É também papel dele despertar o interesse e manter a atenção do aluno. (SCHWARTZ, 2010) para tal. O professor também precisa se reconhecer como sujeito que aprende, pois "só ensina quem aprende" (GROSSI, 1998) e "não há docência sem discência" (FREIRE, 1998). É papel do professor fazer do ensino uma linguagem que favoreça o entendimento do mundo aos alunos, organizando situações didáticas que oportunizem aos sujeitos pensar sobre questões diversificadas, sob diferentes olhares e, assim, aprender a estabelecer relações não lineares com os objetos do conhecimento, atribuindo-lhes significado (SOUZA, D.; SILVA, C. S. S.; BEDIN, E., 2020).

O professor alfabetizador necessita ser empático com os alunos. A empatia tem a ver com a capacidade de se colocar no lugar do outro, com o pensamento do outro. Não é algo do tipo "o que eu faria no lugar dele", mas sim algo como "o que eu faria no lugar dele, com o conhecimento, a vivência dele". Esse "pequeno detalhe" faz toda a diferença na empatia.

Se colocar no lugar do cérebro de alguém que não sabe ler e escrever, sabendo, demanda conhecimento cientificamente conhecido sobre como se aprende e como se ensina essas habilidades! Conhecimento esse que percebe a necessidade da ação do aprendiz, da produção de pensamentos, da testagem de hipóteses, para aprender. Por essas razões é tão importante que o professor alfabetizador reflita criticamente, reveja saberes, estude, se aproprie do conhecimento construído sobre os processos de ensino e de aprendizagem da leitura e da escrita. Sem reconstruir esse conhecimento dificilmente conseguirá ser empático e desenvolver uma prática pedagógica diferente da com que foi 
ensinado e que tão pouca efetividade tem mostrado, vide o número de analfabetos funcionais8 que frequentaram a escola. Por outro lado, é possível ver nos noticiários de televisão pais e mães que atravessam madrugadas à porta de escolas públicas, em filas intermináveis, a fim de garantir uma vaga para seus filhos perto de casa. Essa ação parece representar a valorização, a importância que atribuem à educação para os seus filhos, revelando que a população acredita neste espaço e investe em suas possibilidades. 9

Em relação ao motivo três apontado na pesquisa: crianças têm seu momento certo para aprender a ler e escrever, bem como cada um tem um tempo ou ritmo diferente, inicialmente seria importante conseguir explicar por que os que parecem ter ritmo mais lento se concentram na população menos favorecida economicamente, que é a que parece necessitar de três anos para aprender.

Pesquisas (STERNBERG, 1985, 1998; ALMEIDA, 1992; POZO, 1996) invalidam o argumento da existência do ritmo ou do tempo de cada um para a aprendizagem. Afirmam esses estudos que inteligência não é inata, é processo, quanto mais se aprende mais inteligente se fica. Especificam também que aprender é inerente ao ser humano, todos nascem com potencial para a aprendizagem e que os limites e possibilidades de cada um ainda não foram definidos pela ciência. Indo ao encontro dessas ideias, Demo (2011, p.15) afirma que "todo aluno se alfabetiza bem em um ano, por mais pobre que seja, desde que encontre escola adequada, principalmente professores autores".

Diferentes compreensões sobre como o sujeito aprende têm sido socializadas ao longo da história. Piaget, Vygotsky, Wallon, Freire (1998), entre outros, contribuíram significativamente para a compreensão sobre como o sujeito aprende. Em relação à leitura e à escrita, Ferreiro e Teberosky (1979), apresentando os achados da pesquisa sobre a psicogênese da língua escrita, demonstraram que o sujeito aprendiz é ativo, pensa sobre o mundo ao seu redor e chega à escola com diferentes hipóteses sobre a escrita.

Antes desses teóricos, duas concepções explicavam o conhecimento - o inatismo e o empirismo. O inatismo é coerente com a ideia de ritmo (ou tempo) de aprendizagem, pois "nessa concepção, a aprendizagem tem uma velocidade que está associada à idade, à

\footnotetext{
${ }^{8}$ Disponível em www.ipm.org.br/pt-br/programas/inaf/relatoriosinafbrasil - acessado em 30/07/2016 ${ }^{9}$ Recomendo assistir o vídeo Que letra é essa, disponível em https://www.youtube.com/watch?v=NtyL4NEEIEE (vários acessos), que também contribui na percepção da valorização da escola pelos pais, desvelando alguns preconceitos.
} 
maturação, ao desenvolvimento 'natural', a uma evolução quase biológica, o que justifica a organização das turmas por faixa etária”. (GROSSI, 1998 p. 9).

Contrariando também a ideia de ritmo ou tempo pessoal de aprendizagem, Vergnaud (2008) apresenta o conceito de esquema de pensamento, afirmando que nossos esquemas contêm ao mesmo tempo a ideia do que é conhecido, reconstruído da experiência vivenciada e a percepção do novo, do diferente, da incompletude, que encaminha a possibilidade de enfrentar situações inesperadas.

Afirma esse autor que, diante de situações inusitadas, o sujeito não se percebe completamente despreparado, pois pode recorrer ao repertório de esquemas de pensamento já elaborados, combinando e recombinando elementos de outros esquemas, elaborando hipóteses para solucionar, mesmo que provisoriamente, o problema. Neste sentido, aprender pressupõe movimentos de ruptura/continuidade com o conhecimento prévio anterior e sua articulação/confrontação com a realidade que se apresenta naquele momento.

Em relação à alfabetização, o que alguns professores percebem como ritmo, parece ser fruto de confusão com a diferença de conhecimento sobre a escrita que o aluno desenvolve antes de ingressar na escola e traz para a sala de aula. Conhecimento esse dependente/autônomo (MORIN, 2000) da qualidade das interações que desenvolve com a cultura escrita, cujo potencial determinante será no sentido de oportunizar que o sujeito chegue à escola com um conhecimento mais ou menos elaborado sobre a escrita.

As crianças que frequentam escolas particulares geralmente se alfabetizam em um ano letivo, com raríssimas exceções, e para as das classes mais pobres, muitas vezes, nem os três anos são suficientes. Assistir em casa aos diferentes usos que essas habilidades têm e trazem, as vivências em um ambiente alfabetizador mais rico, podem ser fatores com potencial determinante para que a aprendizagem da leitura e da escrita aconteça, mesmo antes do ingresso na escola ou em um ano letivo.

Em síntese, pesquisas confirmam que sujeitos que têm oportunidade de vivenciar cotidianamente práticas sociais de linguagem antes da chamada idade escolar não apresentam, estatisticamente, problemas de não aprendizagem da leitura e da escrita. Isso não significa que o sujeito que teve oportunidade de vivenciar um ambiente alfabetizador rico de diferentes portadores de texto tenha mais facilidade em aprender ou que ele seja mais inteligente, mas sim que as hipóteses que já elaborou sobre a escrita e a leitura, seus esquemas de pensamento estão mais avançados antes do ingresso na escola, que os dos sujeitos que não tiveram oportunidade de vivenciar um ambiente alfabetizador. 
Ciente desse fato, o professor precisa planejar e desenvolver estratégias metodológicas, com base no conhecimento cientificamente construído sobre o tema, para diagnosticar os saberes que seus alunos já trazem, para intervir de modo que se parta desse conhecimento para fazê-lo avançar de forma significativa, pois "[...] sendo a escrita uma maneira particular de transcrever a linguagem, tudo muda se supomos que o sujeito que vai abordar a escrita já possui um notável conhecimento de sua língua materna, ou se supomos que não o possui”. (FERREIRO; TEBEROSKY, 1979, p.23).

A percepção da importância do ambiente alfabetizador vivenciado anteriormente ao ingresso na escola, nos encaminha para o pressuposto de que é preciso reconstruir, ao longo do ano letivo, as vivências que os sujeitos que aprendem a ler e escrever tiveram, planejando situações que oportunizem a percepção das possibilidades de usos e funções dos diferentes portadores de textos, desencadeando a construção de um ambiente alfabetizador a partir do início do ano escolar. Porém, não é suficiente criar um ambiente alfabetizador para que uma pessoa se alfabetize. Se assim fosse não haveria analfabetos nas cidades onde a cultura escrita está presente. É preciso sistematizar intervenções específicas que provoquem o pensamento do aprendiz sobre esse conteúdo, pois não basta estar em contato com o objeto escrita para garantir a alfabetização (FERREIRO; TEBEROSKY, 1979).

Com base nessa análise dos motivos apontados pelos professores alfabetizadores para a não aprendizagem da escrita, seria possível afirmar que os responsáveis pela formação inicial de professores alfabetizadores necessitam encaminhar reflexões críticas sobre os egressos dos seus cursos, repensar sua composição curricular, escutar os discentes e suas percepções sobre sua formação, incluindo a participação em programas e projetos, se estão contribuindo positivamente na qualidade das aprendizagens.

\section{CONSIDERAÇÕES (QUASE) FINAIS}

Devemos ensinar explicitamente as crianças a converter letras em sons? Sim,
claro. Essa é uma das principais habilidades que os bons leitores adquirem.
Devemos ensinar as crianças a ler textos fáceis com palavras familiares? Sim,
claro. É desse modo que elas desenvolvem fluência e automatismo. Devemos
nos concentrar em ensinar vocabulário e conteúdo? Sim, claro. É assim que elas
desenvolvem o conhecimento que sustenta a compreensão. Devemos expor as
crianças a histórias instigantes? Sim, claro. É assim que elas aprendem sobre
narrativas e se sentem mais motivadas a ler. Todas as divergências sobre o
ensino de leitura começam com a alegação de que é preciso fazer uma ou outra 
dessas coisas no começo da alfabetização. Na verdade, temos de fazer tudo isso $(\mathrm{SNOW}, 2019)^{10}$

Ensinar e aprender a ler e a escrever em um ano letivo é possível. Uma evidência disso pode ser percebida na análise dos índices dessas aprendizagens em escolas particulares, nesse espaço de tempo. Considerando isso, podemos nos questionar: por que os altos índices de não aprendizagem estão localizados nas camadas mais carentes economicamente da população? Qual o principal diferencial entre os alunos ingressantes no $1^{\circ}$ ano das escolas particulares e das municipais e estaduais? O ambiente alfabetizador vivenciado antes do ingresso na escola parece ter potencial determinante no futuro das aprendizagens.

Nesse sentido, em vez de desenvolver estratégias paliativas como o aumento do tempo, com a inserção de mais um ano de escolaridade, para que essas aprendizagens se concretizem nas escolas denominadas públicas, não seria mais adequado, dentre outras ações, repensar os cursos de formação inicial e continuada dos professores alfabetizadores?

Ações que englobam desde a formatação curricular desses cursos, modificando prioridades, dividindo equitativamente componentes que visam analisar, planejar, desenvolver práticas pedagógicas bem-sucedidas, complementados por outros que oportunizem a compreensão da teoria que sustenta essas ações, de modo que os alunos dos cursos de licenciatura vivenciem situações para reconstruir e ressignificar os achados teóricos sobre o tema, poderiam contribuir para modificar esse panorama.

Reestruturar esses cursos desde detalhes como aulas obrigatoriamente teóricas e outras práticas, com objetivos de aprendizagem explicitados nos planos de ensino de cada componente curricular, coerentes com competências e habilidades a serem reconstruídas ao longo do processo, culminando, cada semestre com um produto combinado entre os diferentes componentes do semestre e com a participação dos alunos, para contribuir para a atribuição de sentido e significado nas tarefas acadêmicas, seriam algumas sugestões possíveis de serem planejadas em diferentes contextos.

Os motivos apontados pelos professores para justificar a não aprendizagem da leitura e da escrita precisam ser analisados e discutidos ao longo do curso de formação inicial, oportunizando que os sujeitos observem e descrevam práticas, analisem detalhes referentes a elas, partindo de aspectos como planejamento, intervenções didáticas, avaliação, articulando com a fundamentação teórica sobre o tema e elaborando conclusões

\footnotetext{
${ }^{10}$ Disponível em http://alfabetizacao.mec.gov.br/20-o-que-dizem-as-pesquisas/34-catherine-snow\#item acessado em 12/03/2020.
} 
consistentes e justificadas. Para tal, os professores formadores precisariam corporificar as palavras pelo exemplo em suas próprias práticas com os licenciandos, pois não é suficiente defender concepções inerentes a uma base teórica e desenvolver, algumas vezes, práticas incoerentes com ela.

Diferente de habilitar os alunos a repetir e memorizar conhecimento teórico, tornando-os reféns de ideias alheias, seria adequado oportunizar que eles possam reconstruir, ressignificar o conhecimento cientificamente construído sobre como se ensina, como se aprende a ler e escrever, contribuindo para o planejamento, a execução e a avaliação continua da prática pedagógica alfabetizadora.

Para tal, os alunos precisam analisar criticamente o conhecimento cientificamente construído, de modo a ser capaz de identificar e escolher conscientemente a concepção teórica que é coerente com sua maneira de ver o mundo, os sujeitos que nele habitam, que tipo de aluno desejam contribuir para formar, que tipo leitores, que tipo de escritores. Assim, quando em situações de estágios ou similares, quem sabe terão elaborados argumentos consistentes para dialogar com os professores que já atuam e, quem sabe, convencê-los de que mudar é preciso, em vez de se submeterem a algo em que não acreditam.

Esse texto se propôs a contribuir para avanços para o ensino e a aprendizagem da leitura e da escrita, analisando as evidencias científicas que contribuem para isso. Ao analisar os motivos apontados por professores alfabetizadores para explicar as razões de alguns alunos aprenderem a ler e a escrever em um ano letivo e outros não, podemos perceber que muitos desconhecem as evidencias cientificas que encaminham para o ensino adequado da alfabetização.

Acreditamos que uma das maneiras de modificar isso seria que os cursos de licenciatura se dedicassem mais a explicar/compreender/reconstruir/ressignificar as

mais recentes descobertas sobre os processos de ensino e de aprendizagem, se preocupando em desconstruir ideários que perpassam o senso comum, que se referem a maneiras de ensinar e aprender antigas, reprodutoras de um jeito de ensinar e de aprender que aconteciam em outros contextos, diferentes dos atuais.

Seguimos nosso trabalho com a esperança de mobilizar outros sujeitos a se engajar na qualificação da educação com comprometimento e coerência. Sabemos que alcançar esse objetivo depende de inúmeros fatores, não apenas educacionais, de diferentes ângulos de análise, mas, se o engajamento em torno do objetivo de formar pessoas habilitadas a ler, compreender, produzir diferentes tipos e gêneros textuais, quando necessitarem e/ou 
desejarem e que possam utilizar esse conhecimento para qualificar suas vidas for de muitas pessoas, unas/diversas, mas com a mesma meta e tendo clareza dela, pode ser que consigamos contribuir para modificar os índices de não aprendizagem e realizar o feito de alfabetizar com qualidade todos alunos em um ano letivo.

\section{REFERÊNCIAS}

ALMEIDA, L. S. Inteligência e Aprendizagem: dos seus Relacionamentos à sua Promoção. In: Psicologia: Teoria e Pesquisa, v. 8, n. 3, 1992, p. 277-92.

BISQUERRA, R. Métodos de investigación educativa. Barcelona: Ceac, 2000.

CLAXTON, G. Live and Learn. A Introduction to the Psychology of Growth and Change in Everyday Life. London: Harper \& Row, 1984.

COLLELO, S. A escola que (não) ensina a escrever. São Paulo: Paz e Terra, 2007.

DEMO, P. Metodologia para quem quer aprender. São Paulo: Atlas, 2008.

DEMO, P. O mais importante da educação importante. São Paulo: Atlas, 2012.

FERREIRO, E.; TEBEROSKI, A. Psicogênese da língua escrita. Porto Alegre: Artes Médicas, 1979.

FERREIRO, E. Alfabetización, teoría y práctica. 5 ed. Mexico: Siglo Veintiuno, 2002.

FREIRE, M. Educador. São Paulo: Paz e Terra, 2008.

FREIRE, P. Professora sim, tia não: cartas a quem ousa ensinar. São Paulo: Olho d'Água, 2000.

FREIRE, P. Pedagogia da Esperança, um reencontro com a pedagogia do oprimido. $5^{a}$ edição. Rio de Janeiro: Paz e Terra, 1998.

GADOTTI, M. Alfabetização e letramento tem o mesmo significado? In: Revista Pátio, ano IX, mai/jul/2005, p.48-52

GATTI, B.A. et al. Formação de professores para o ensino fundamental: instituições formadoras e seus currículos; relatório de pesquisa. São Paulo: Fundação Carlos Chagas; Fundação Vitor Civita, 2008. 2v.

GROSSI, E. Nova Falácia Criminosa. Zero Hora, 8 e 9 de abril de 2017, p.26

GROSSI, E.[et al]. Ensinando que todos aprendem. Revista do GEEMPA, no. 6: Ensinando que todos Aprendem, Porto Alegre: Edelbra Indústria Gráfica, (p.3-6),1998.

LYRA, L.R.; CUSTÓDIO, J.F. DOI: https://doi.org/10.36661/25954520.2019v2i4.11036 O Professor Formador e Suas Crenças Didático-Pedagógicas. IN: 
RIS|:Revista Insignare Scientia, Universidade Federal da Fronteira Sul, Cerro Largo, RS, Vol. 2, n. 4. Set./Dez. 2019.

MARTINS, L.M; DUARTE, N. Formação de professores: limites contemporâneos e alternativas necessárias. SP: (org). Cultura Acadêmica, 2010.

MORAES, R. Uma Tempestade de Luz: a Compreensão Possibilitada Pela Análise Textual Discursiva. (2003). Disponível em http://www.scielo.br/pdf/ciedu/v9n2/04.pdf, acessado em 01 de maio de 2015.

MORIN, E. O Método III: o Conhecimento do Conhecimento. 2 ed. Porto Alegre: Sulina, 1999.

MORIN, E. O método VI: a ética. Porto Alegre: Sulina, 2005.

MORIN, E. Os Sete Saberes Necessários à Educação do Futuro. São Paulo: Cortez, 2000.

NEMIROVSKY, M. Entrevista pessoal gravada e transcrita em Madrid. mai. 2005.

POZO, J. I. Estratégias de Aprendizagem. In: COLL, C.; PALÁCIOS, J.; MARCHESI, A. (orgs.). Desenvolvimento psicológico e educação: psicologia da educação. Porto Alegre: Artes Médicas, 1996, p. 176-97.

SCHWARTZ, S. Alfabetização de jovens e adultos: teoria e prática. RJ, Petrópolis: Vozes, 2010.

SCHWARTZ, S. Entre a Indignação e a Esperança: Motivação, Pautas De Ação Docente, Orientação Paradigmática na Alfabetização de Jovens e Adultos/As. Tese de doutorado. PUCRS, 2007.

SCHWARTZ, S. Motivação e aprendizagem: avanços na prática pedagógica. Ciências e Letras, Porto Alegre, v.32, 2002. p.117 - 132.

SCHWARTZ, S. Motivos para aprender a ler e a escrever. Ciências \& Letras, Porto Alegre, $n^{\circ}$ 38. 2006. P.161-178.

SCHWARTZ, S. Receita para ensinar/aprender a ler e a escrever In: ABRAHÃO, M.H.M.B. (org.)Professores e alunos: aprendizagens significativas em comunidades de práticas educativas. Porto Alegre: EDIPUCRS, 2009, p. 161-182.

SCHWARTZ, S. Quando o que parece óbvio em alfabetização não é tão óbvio assim. Educação e Cidadania, Edições Científicas Ritter dos Reis. Ano 7, nº 7, 2005, p. 59-78.

SCHWARTZ, S. A Educação Infantil tem conteúdos? Ciências \& Letras, Porto Alegre, v.43, 2008. p. $229-246$.

SOARES, M. Letramento e alfabetização: as muitas facetas. Disponível em http://www.scielo.br/pdf/rbedu/n25/n25a01.pdf, acessado em 06/08/2016. 
SOUZA, D.; SILVA, C. S. S.; BEDIN, E. DOI: https://doi.org/10.36661/25954520.2020v3i1.11250. A relevância da observação na formação inicial docente com vistas no desenvolvimento da prática reflexiva. IN: RIS|:Revista Insignare Scientia, Universidade Federal da Fronteira Sul, Cerro Largo, RS, v. 3 n. 1, 2020.

STERNBERG, R. J. Beyond IQ: A Triarchic Theory of Human Intelligence. New York: Cambridge University Press, 1985.

STERnBERG, R. J. Principles of Teaching for Successful Intelligence. Educational Psychologist, v. 33, n. 2/3, 1998, p. 65-72.

TARDIF, M. Saberes docente e formação profissional: Petrópolis, Vozes, 1999.

TEBEROSKY, A. Entrevista pessoal em Barcelona, gravada e transcrita. abr. 2005.

TOLCHINSKY, L. Entrevista pessoal em Barcelona, gravada e transcrita. abr. 2005.

VERGNAUD, G. Atividade humana e conceituação. Porto Alegre: GEEMPA, 2008.

WEISZ, T. A aprendizagem do sistema de escrita: questões teóricas e didáticas. Revista Veras, São Paulo, v. 6, n. 1, p. 11-20, janeiro/junho, 2016.

\footnotetext{
${ }^{i}$ Doutora em Educação pela PUCRS (Pontifícia Universidade Católica do Rio Grande do Sul, 2007) com estágio de doutoramento na Faculdade de Psicologia da Universidade Autônoma de Madrid (UAM - 2005) e pós doutorado na mesma instituição (UAM - 2014). Mestre em Educação pela PUCRS (2001). Professora Adjunta da UNIPAMPA (Universidade Federal do Pampa). Integrante do Núcleo de Educação de Jovens e Adultos (PUCRS). Orientadora de projetos de ensino, pesquisa e de extensão que abordam temas relacionados com alfabetização, cultura escrita, formação de professores, metodologia de pesquisa em educação, alfabetização acadêmica, educação de jovens e adultos. Autora de livros, coordenadora da coleção Compreensão Leitora, tradutora, parecerista da Editora Vozes.
}

ii Atualmente é Professor Associado da Universidade Federal do Pampa, atuando nos cursos de Pedagogia e Geografia. Foi Assessor Especial do Núcleo Estruturante da Política de Inovação (NEPI) do Instituto Federal Goiano/SETEC/MEC. Foi Diretor Geral Pro Tempore do CEFET-RJ no segundo semestre de 2019. Foi assessor e Diretor de Programa Substituto da Secretaria Executiva do Ministério da Educação (MEC), no primeiro semestre de 2019. Foi Vice-Reitor eleito da Universidade Federal do Pampa gestão 20152019. Atuou também como Diretor eleito e Coordenador Acadêmico eleito do Câmpus Jaguarão (20092014), além de coordenar cursos de graduação e pós-graduação. Foi conselheiro eleito e vice-presidente do Conselho Universitário da Universidade Federal do Pampa. Atuou no Instituto Federal Sul-riograndense de 1995 a 2009, participando de vários grupos e comitês. Foi coordenador de curso de pós-graduação no Instituto. Foi cedido à prefeitura de Pelotas, como assessor da Secretaria Municipal da Educação de 20042009. Autor de dois livros na área de educação ambiental e projetos educativos e de capítulos de livros na área da educação integral. Doutor em Educação (PUC/RS, 2009). Mestre em Educação (FURG, 2002). Licenciado em Física (UFPEL, 1999). Especialista em Psicopedagogia Institucional pela Portal Faculdades. Orientador, colaborador e avaliador em projetos de ensino, pesquisa e extensão em cursos de graduação e pós-graduação, que abordam temas relacionados com formação docente, gestão acadêmica universitária, educação integral, gestão das práticas docentes, metodologia de pesquisa em educação e educação em ciências e matemática. Foi docente permanente do Programa de Pós-Graduação Mestrado Profissional em Educação da Unipampa. Foi integrante de vários Conselhos Municipais e estaduais do Rio Grande do Sul. Integrante voluntário da Agenda 2020/RS. Foi conselheiro suplente do Conselho de Administração da SUFRAMA da Superintendência da Zona Franca de Manaus. Foi conselheiro titular do Consórcio CECIERJ e CEDERJ/RJ. É conselheiro titular do Conselho de Administração da FAETEC/RJ.

iii Possui graduação em Licenciatura Em Pedagogia Séries Iniciais pela Universidade Federal do Rio Grande do Sul (1992), mestrado em Educação pela Universidade Federal do Rio Grande do Sul (1999) e doutorado em Educação pela Universidade do Vale do Rio dos Sinos (2008). Tem experiência na educação básica 
estadual e municipal, tendo atuado durante 20 anos na Rede Municipal de Porto Alegre. Atuou como assessora pedagógica na EJA, na alfabetização e na gestão durante 8 anos na Secretaria Municipal de Educação de Porto Alegre. Foi conselheira no Conselho Municipal de Educação de Cachoeirinha e presidente do Conselho Municipal de Educação de Jaguarão. Atua no ensino superior desde 1994 tendo larga experiência em instituições públicas e privadas. Durante 5 anos foi presidente da comissão Própria de Avaliação da UNIPAMPA. Atualmente é professora Adjunta III na Universidade Federal do Pampa, professora do Mestrado Profissional em Educação e Diretora do Campus Jaguarão. Atuou como coordenadora de área-Pibid da Coordenação de Aperfeiçoamento de Pessoal de Nível Superior. Na Unipampa tem ampla experiência na gestão sendo membro de vários órgão superiores e tendo atuando em vários espaços de coordenação tais como coordenação do Curso de Pedagogia, coordenação da Especialização em Gestão da Educação Básica, coordenação da Comissão Local de Ensino e coordenação Acadêmica do Campus Jaguarão. Possui projetos de extensão voltados para formação docente e para qualificação de conselheiros municipais de educação. Desenvolve pesquisas na área das políticas educacionais e gestão, alfabetização, letramento e avaliação, em especial avaliações em larga escala e avaliação institucional, sendo líder do Grupo de Estudos e Pesquisa em Políticas, Avaliação e Gestão da Educação-GEPPAGE. 